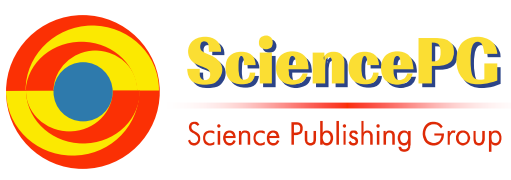

\section{Transfer of grammar strategies from I1 to 12 among Iranian EFL learners regarding their general English proficiency}

\author{
Tayebeh Hatami, Fatemeh Samadi, Abolfazl Akbari, Asghar Ahmadi, Manizhe Agha Rezaee, \\ Morteza Dinari, Fereshte Maleki, Fatemeh Mosavi, Hoshang Koshki
}

M. A. Students of Farhangian University of Arak (Shahid Bahonar branch)

\section{Email address:}

Tayebehhatami61@yahoo.com (Tayebeh Hatami),Fatemehsamadi36@yahoo.com (Fatemeh Samadi)

\section{To cite this article:}

Abolfazl Akbari, Asghar Ahmadi, Manizhe Agha Rezaee, Tayebeh Hatami, Morteza Dinari, Fereshte Maleki, Fatemeh Mosavi, Hoshang Koshki. Transfer of Grammar Strategies from 11 to 12 among Iranian EFL Learners Regarding their General English Proficiency. International Journal of Language and Linguistics. Special Issue: Language Teaching and Learning Key Principles (LTLKP). Vol. 1, No. 4-1, 2013, pp. 68-73. doi: 10.11648/j.ijl1.s.20130101.21

\begin{abstract}
The main aim behind the present study was to know whether teaching some strategies of grammar will have different effect on Iranian EFL learners if they are taught in their first or foreign languages. To this aim, $57 \mathrm{male}$ and 49 female secondary school goers in Markazi province of Iran have been invited into this study. Applying t-test and secretive analysis indicated that there is no difference between genders in learning grammar strategies either in their first or foreign language. It was also indicated that teaching strategies of English grammar either in first or foreign language has the same impact of Iranian EFL learners.
\end{abstract}

Keywords: Tense, Transfer, Gender and Strategy

\section{Introduction}

\subsection{What Is Language?}

Human beings can communicate with each other. We are able to exchange knowledge, beliefs, opinions, wishes, threats, commands, thanks, promises, declarations, and feelings - only our imagination sets limits. We can laugh to express amusement, happiness, or disrespect, we can smile to express amusement, pleasure approval, or bitter feelings, we can shriek to express anger, excitement, or fear, we can clench our fists to express determination, anger or a threat, we can raise our eyebrows to express surprise or disapproval, and so on, but our system of communication before anything else is language. In this book we shall tell you a lot about language, but as a first step towards a definition we can say that it is a system of communication based upon words and the combination of words into sentences communication by means of language may be referred to as linguistic communication, the other ways mentioned above - laughing, smiling, shrieking, and so on - are types of non-linguistic communication. Most or all non-human species can exchange information, but none of them are known to have a system of communication with a complexity that in any way is comparable to language. Primarily, they communicate with non-linguistic means resembling our smiling, laughing, yelling, clenching of fists, and raising of eyebrows. Chimpanzees, gorillas, and orangutan's can exchange different kinds of information by emitting different kinds of shrieks, composing their faces in numerous ways, and moving their hands or arms in different gestures, but they do not have words and sentences. By moving in certain patters, bees are apparently able to tell their fellow workers where to find honey, but apparently not very much else. Birds sing different songs, whose main functions are to defend their territory or to attract a mate Language - as defined above - is an exclusively human property. Among the characteristics that make a relatively clear distinction between linguistic and nonlinguistic communication meaningful, two are 
particularly important: double articulation and syntax.

\subsection{Transfer in Language}

Transfer, derived from the Latin word "transferre", means "to carry", "to bear" or "to print, impress or otherwise copy (as a drawing or engraved design) from one surface to another"(Webster's Third New World International Dictionary, 1986). So to speak, when we say "technology transfer", we mean the transfer or carry-over of technology from one owner to another.

Transfer can also mean "the carry-over or generalization of learned responses from one type of situation to another", especially "the application in one field of study or effort of knowledge, skill, power, or ability acquired in another" (Webster's Third New World International Dictionary, 1986). The use of "transfer" in "linguistic transfer" is such an example. By linguistic transfer, we mean what the learners carry over to or generalize in their knowledge about their native language (NL) to help them learn to use a target language (TL). Here transfer does not indicate whether what is carried over is bad or good. This meaning from the dictionary shows that transfer is a neutral word in origin and nature.

Linguistics concerns, in overall, with the static structures within a language system. Viewed from the TL grammatical rules, certain NL-based linguistic transfers are found to coincide with linguistic errors. In this way, NLbased linguistic transfers are divided into two broad types, positive and negative. Those NL-based uses that do not lead to linguistic errors are labeled as positive transfer, whereas those that leads to errors, negative transfer. In second language classroom teaching, a positive linguistic transfer is generally not attacked, but a negative linguistic transfer, almost to all instructors, is definitely not recommended for the learners, since it is erroneous.

In practice, transfer has attracted people of different academic backgrounds and led researchers to different interpretations and definitions of the term. Scarcella (1990), for instance, was interested in the transfer of discourse accent and believed that it is a reflection of 'conversational features' such as forms and functions of conversational management. Whereas transfer refers to those linguistic behaviors incorporated from L1 into IL without capturing other inter-lingual effects, cross-linguistic influence, on the other hand, refers to those L1 effects such as avoidance, L1 constraints on L2 learning and performance, and different directionality of inter-lingual effects. Generally speaking, transfer just means the influence resulting from similarities and differences between the target language and any other language that has been obviously, and perhaps imperfectly, acquired. This definition thus suggests that transfer can occur at any levels, strategic, linguistic, discourse, and pragmatic. In Beebe et al 's opinions (1990), transfer specifically refers to the learners' L1 socio-cultural competence in performing L2 speech acts or any other aspects of L2 conversation. Hence for Clyne et al (1994), "apologies" and "complaints" are pragmatic, while turn- taking discourse. In terms of the scope of transfer, Beebe et al (1990) held that transfer consists of both cross-linguistic influence and cross-cultural transfer elements. Kasper (1995) focused on pragmatic transfer and defined it as "the influence exerted by learners' pragmatic knowledge of languages and cultures other than L2 on their comprehension, production, and acquisition of L2 pragmatic information" (Kasper, ibid).

The usual way to identify a transfer in SLA research is something like an informal estimation method (Kasper, 1995). In informal estimations, we decide whether a transfer can be established by looking at the similarities and differences of the percentage by which a particular category of inter-language features (such as a semantic formulae, strategy, or linguistic form) occurs in the NL, TL, and IL data.

\subsection{The Impact of Gender on Language Learning}

Males and females learn differently from each other. Males tend to be more kinesthetic, tactual, and visual, and need more mobility in a more informal environment than females. Males also are more nonconforming and peer motivated than their female classmates. In group, males tend to learn less by listening. Females, more than males, tend to be auditory, authority-oriented, and better able to sit passively at conventional classroom desks and chairs than males. Females also tend to:

- need significantly more quiet while learning (Pizzo, 1990: 11);

- be more self- and adult -motivated, and conforming than males (Marcus, 1977: 9).

According to Thompson (1975), boys learn to compete in hierarchical groups, while girls learn to cooperate in small groups in which mutual liking is important. We as teachers of English know that one of the important parts of learning the language is decision making, and in this area again we can see contrasting worlds. Ong (1989) suggests that the male world is based on "adversative", in contrast, females are encouraged to keep the peace, provocative, challenging, and aggressive, while males see the suggestions that females make as infuriating and bossy. Males appear to want females to act like males, and females want males to act like females. During the problem solving, which we often face at the English lessons, there are clear differences between boys and girls (Dorval, 1990). As far as body language was concerned, boys sat at angles to each other and their gaze was not anchored on the other's face, while the girls sat close together and their gaze was anchored on the other's face.

\subsection{Based on What Has Been Discussed above the Following Hypotheses Are Formulated}

1-Teaching English grammar strategies in Iranian learners 'mother tongue has more effect on their grammar proficiency than in foreign language.

2-Teaching English grammar strategies in Iranian 
learners 'mother tongue has different effect on Iranian English learners with different genders.

\section{Methodology}

\subsection{Subjects}

A sample of secondary school students (grade three) governmental schools with English as medium of instruction in the city of Arak, Iran comprised the participants of the present study. They were of 14 to 15 years of age. These schools were randomly selected.

The participants were categorized as:

Group A (29 male and 25 female said Persian grammar)

Group B (28 male and 24 female said English grammar)

In the present study a dominant bilingual is a person being more proficient in one of the two languages (in most cases native-like), in this particular case, those participants who are able to communicate in schools but are more dominant in Persian. While a balanced bilingual is someone who is more or less equally proficient in both languages, but will not necessarily pass for a native speaker in both languages. In this study those participants whose mother tongue is Persian and also are native-like in Iran, have been considered as balanced bilinguals. That is, albeit they are native speakers in Persian, they competently use it in their daily conversations. Participants, in all groups were homogenous, in terms of their age, methodology used at schools, and the number of hours devoted to the teaching of English. To get the above mentioned objectives some materials as Nelson test and grammar test were administered.

\subsection{Procedure}

To achieve the objectives of this study the following procedures were adopted:

At the very beginning of the research, the background questionnaire was given to the subjects and make sure of their appropriate age and grade. Then they were given a pretest in English grammar to check their level of knowledge in that particular grammar which contained two tenses as past continues tense and simple future. After giving the subjects enough treatment the post test was applied. To make sure of the subjects homogeneity, the Nelson test was administers to pick those subjects who are the same in English proficiency.

\section{Results and Discussion}

Having collected the data, the present researchers place them in SPSS software; therefore, the following output was arrived at. All in all the data analysis indicated:

-There is no significant difference between teaching English grammar strategies either in the learners/ mother tongue or foreign language.

- Teaching English language in mother tongue or in English language has same effect on male and female school students.

-Iranian male and female learners performed equally in English grammar strategies teaching in both languages.

In order to analyzing research hypotheses, difference between teaching English language in mother tongue and in English language on male and female secondary school students, we can use analyzing variance with repeated measurement because of two dependent variables (pretest and posttest) and also independent variables. Dependent variables have been measured in two different times (pretest and posttest) and by two different teaching methods (teaching in mother tongue and in English language) from two groups (male and female students). In table below, Descriptive Statistics of aforementioned variables has been presented which there are mean, Standard Deviation and number of scores in pretest and posttest of teaching English language in mother tongue and in English language on male and female secondary school students.

Table1: Descriptive Statistics

\begin{tabular}{|c|c|c|c|c|c|}
\hline & Class & Gender & Mean & Std. Deviation & $\mathrm{N}$ \\
\hline \multirow{6}{*}{ Pre-test } & \multirow{3}{*}{ Persian } & Female & 3.52 & 2.519 & 25 \\
\hline & & Male & 2.07 & 1.067 & 29 \\
\hline & & Total & 2.74 & 2.002 & 54 \\
\hline & \multirow{3}{*}{ English } & Female & 3.38 & 1.279 & 24 \\
\hline & & Male & 3.14 & 1.840 & 28 \\
\hline & & Total & 3.25 & 1.595 & 52 \\
\hline \multirow{12}{*}{ Post-test } & \multirow{3}{*}{ Total } & Female & 3.45 & 1.990 & 49 \\
\hline & & Male & 2.60 & 1.580 & 57 \\
\hline & & Total & 2.99 & 1.823 & 106 \\
\hline & \multirow{3}{*}{ Persian } & Female & 6.32 & 4.732 & 25 \\
\hline & & Male & 6.72 & 4.131 & 29 \\
\hline & & Total & 6.54 & 4.381 & 54 \\
\hline & \multirow{3}{*}{ English } & Female & 5.88 & 3.710 & 24 \\
\hline & & Male & 9.79 & 6.027 & 28 \\
\hline & & Total & 7.98 & 5.414 & 52 \\
\hline & \multirow{3}{*}{ Total } & Female & 6.10 & 4.224 & 49 \\
\hline & & Male & 8.23 & 5.332 & 57 \\
\hline & & Total & 7.25 & 4.945 & 106 \\
\hline
\end{tabular}

Table 1 shows that mean and SD of pretest and posttest of female students in teaching English language in mother tongue are 3.52 and 2.519, respectively. Also, mean and SD of pretest and posttest of male students in teaching English language in mother tongue is 2.07 and 1.067, respectively. Also ,for some other examples, that mean and SD of pretest and posttest of female students in teaching English language in mother tongue are 6.32 and 4.732 in above table and mean and SD of pretest and posttest of male students in teaching English language in mother tongue are 6.72 and 4.131 that these numbers are equal in two groups approximately but they are different from pretest scores.(It can be record other numbers in table 1). Because pre hypothesis of analyzing variance with repeated measurement is equal to observed equality of covariance 
matrices, it can be presented Box's Test:

Table2: Box's Test of Equality of Covariance Matrices

\begin{tabular}{c|c}
\hline Box's M & 29.632 \\
F & 3.175 \\
df1 & 9 \\
df2 & 108111.966 \\
Sig. & .001 \\
\hline
\end{tabular}

Regarding big amount of fisher item (3.175) and small amount of meaningful level ( $\mathrm{sig}=0.001$ ), it can be conclude from above table that $\mathrm{H} 0$ is rejected in 0.05 . It means, Covariance Matrices is not equal in different groups. So, we can refer to Levene's table below:

Now, for analyzing pre hypothesis of analyzing variance with repeated measurement, it can be used table 3 by Levene's test for measuring Equality of Error Variances.

Table 3: Levene's Test of Equality of Error Variances

\begin{tabular}{ccccc}
\hline & F & df1 & df2 & Sig. \\
\hline Pre-test & 2.511 & 3 & 102 & .063 \\
Post-test & 1.245 & 3 & 102 & .075 \\
\hline
\end{tabular}

a. Design: Intercept + Class + Gender + Class * Gender

Within Subjects Design: Time

With regard to recorded $\mathrm{f}$ values $(2.511,1.245)$ and meaningful level(sig $)(0.063,0.075)$,above table determined that there is not special reason for rejecting $\mathrm{H} 0$ ( Equality of Error Variances).As a result, pretest and posttest Error Variances teaching English language in mother tongue or in English language for male and female students is equal to hypothesis.

Another important pre hypothesis is analyzing variance with repeated measurement that is form of dependent variables in variance and Covariance Matrices should be hemisphere. Regarding dependent variable which has two levels, it has hemisphere shape. It means this pre hypothesis is correct. The value of being hemisphere is equal to one that is called complete hemisphere.

Now by using two pre hypotheses, it would be possible to do analyzing variance with repeated measurement. In order to measure the meaningful level of internal effect of time variable, it can be used a table which contains it.

Table 4: Tests of Within-Subjects Effects

\begin{tabular}{cccccc}
\hline Source & $\begin{array}{c}\text { Type IV Sum } \\
\text { of Squares }\end{array}$ & df & $\begin{array}{c}\text { Mean } \\
\text { Square }\end{array}$ & F & Sig. \\
\hline Time & 907.045 & 1 & 907.045 & 87.905 & .000 \\
Time * Class & 9.378 & 1 & 9.378 & .909 & .343 \\
Time * Gender & 118.449 & 1 & 118.449 & 11.479 & .001 \\
Time * Class * & 17.231 & 1 & 17.231 & 1.670 & .199 \\
Gender & 1052.490 & 102 & 10.319 & & \\
Error(Time) & & & & & \\
\hline
\end{tabular}

Measure: Grammar

Based on meaningful level in first row of table $4,(\mathrm{sig}=0.000)$, for analyzing the effect of teaching English language in mother tongue or in English language, it would be conclude that this effect is meaningful in every error level. In other word, post test scores are better than pre test scores. It means, teaching English language (in mother tongue or in English language) is effective on students and using one of these two method is useful in learning grammar of students. Also, with regard to meaningful level in second row, $(\mathrm{sig}=.343)$, for effect of time and method of teaching variables, it can be observed that this effect is not meaningful in any level. In other word, there is no significant difference between two methods. As a result, student ' grammar scores improved equally by using two methods. So, there isn't any reason for rejecting H0 (There is no significant difference between teaching English language in mother tongue and or in English language on guide school students) in H1.So,the claim in first hypothesis that is the same effect of teaching English language in mother tongue or in English languages accepted. For better understanding of above materials, you can observe figure 1:

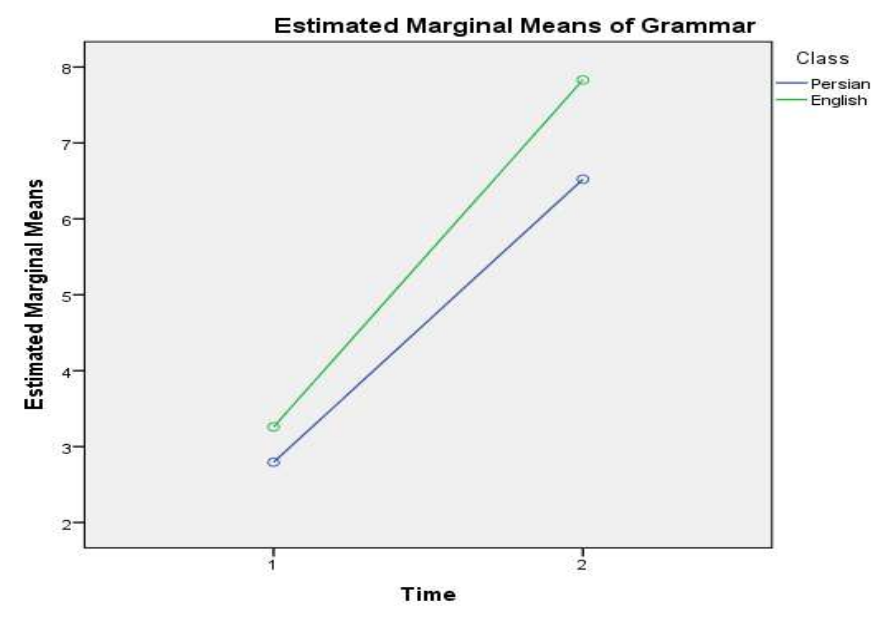

Figure1: Linear diagram of shows pretest (1) and posttest(2) of Teaching English language in mother tongue (purple line) and in second language(green line) 
Fig 1 shows Linear diagram of marginal means which expected from scores in pretest and posttest of Teaching English language in mother tongue (purple line) and in second language(green line).In above diagram ,the difference is clear between scores1 (pretest) and 2 (posttest).It means teaching English language is effective on improving students' grammar scores. However, there is no significant difference between green line (teaching in second language) and purple line (teaching in mother tongue), so there is not any difference between two methods. As a result, students' grammar scores improved equally by two methods. So there is not any reason for rejecting H0 (There is no significant difference between teaching English language in mother tongue and in English language on junior secondary school students) in H1. In order to examining meaningful test in the equilibrate effect of gender and teaching method variables in model, table 5 has been used.

Based on meaningful level in last column of table 5 ( $\operatorname{sig}=0.031$ ), test of equilibrate effect is observable in teaching method variable (mother and second language) and gender variable on mean of grammar. In other word,

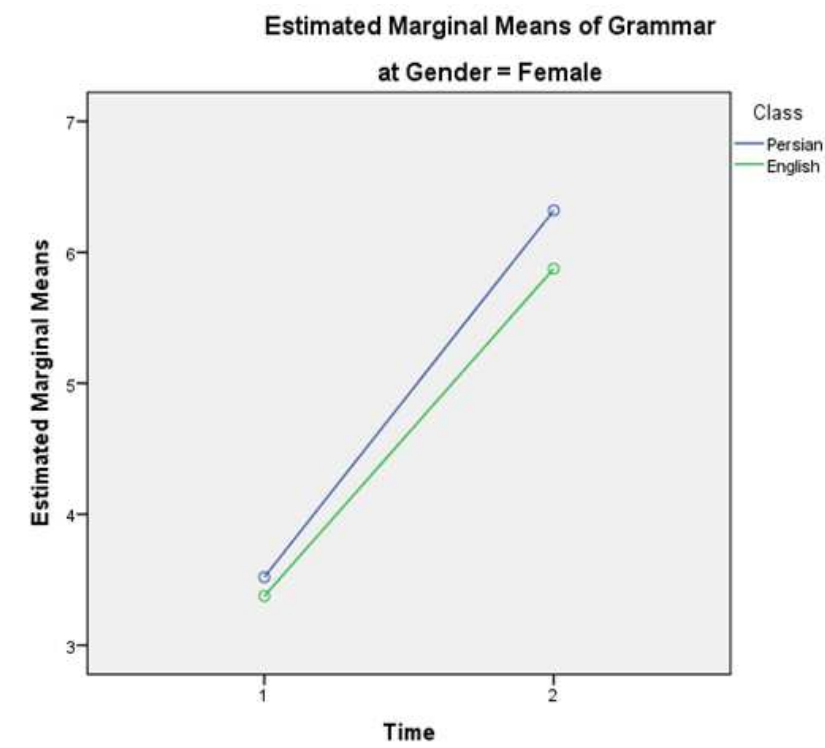

there is meaningful difference between mean score of grammar based on two methods of teaching for male and female students. So, the rate of effectiveness is different in teaching English language in mother tongue and second on students' grammar scores.

Table 5: Tests of Between-Subjects Effects

\begin{tabular}{cccccc}
\hline Source & $\begin{array}{c}\text { Type IV Sum } \\
\text { of Squares }\end{array}$ & df & Mean Square & F & Sig. \\
\hline Intercept & 5483.841 & 1 & 5483.841 & 355.542 & .000 \\
Gender & 22.802 & 1 & 22.802 & 1.478 & .227 \\
Class & 41.387 & 1 & 41.387 & 2.683 & .104 \\
Gender * Class & 73.520 & 1 & 73.520 & 4.767 & .031 \\
Error & 1573.238 & 102 & 15.424 & & \\
\hline
\end{tabular}

As a result, H0 in second hypothesis (There is no significant difference between teaching English language in mother tongue and or in English language on male and female guide school students) is rejected. For better understanding, graphic diagram is presented:

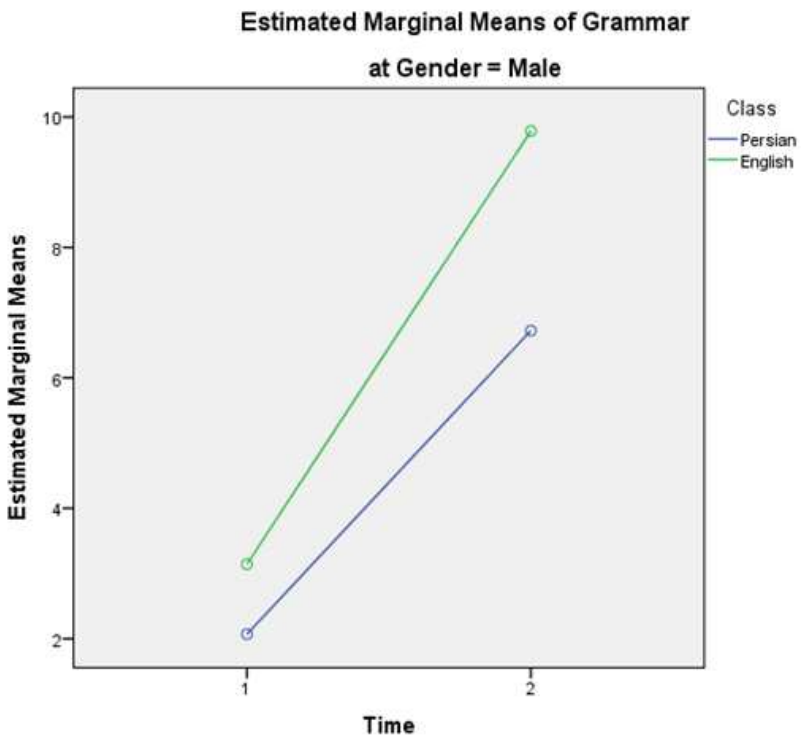

Fig2: Linear diagram of mean scores in pretest (1) and posttest (2) of teaching English language in mother tongue (purple line) and second language(green line) between female students(above diagram) and male students (below diagram)

Figure 2 indicates linear diagram of mean scores in pretest (1) and posttest (2) of teaching English language in mother tongue (purple line) and second language (green line) between female students (above diagram) and males (below diagram).With regard to reversed resting of green and purple lines in two diagrams, it is observable that learning methods have different effect on mean scores of grammar scores in male and female students. In other words ,the rate of effectiveness is different in teaching English language in mother tongue and second language between male and female students .So, H0(There is no significant difference between teaching English language in mother tongue and in English language on male and female Junior secondary school students) in $\mathrm{H} 2$ is rejected.

\section{References}

[1] Beebe, L.M., Takahashi, T., \& Uliss-Weltz, R. (1990). Pragmatic transfer in ESL refusals . Amsterdam: Benjamins Publication.

[2] Clyne, M., Giannicos, C., \& Neil, D. (1994). Cross-cultural responses to cross-cultural communication [J]. In ITL 9: 103-104, 1-17. 
[3] Dorval, B. (1990) Conversational Coherence and its Development. Norwood, NJ: Ablex G.

[4] Kasper (1995). Strategies in interlanguage communication. London: Longman, 119-139.

[5] Marcus, L. (1977). A Comparison of Selected Ninth-grade Male \& Female Students' Learning Styles. New York: Oxford University Press.

[6] Ong, W. (1989). Fighting for Life: Contest, Sexuality, and Consciousness. NY: Cornell University Press.
[7] Pizzo, J. (1990). Responding to Students' Learning Styles. St. John's University. NY

[8] Scarcella, R. C., Andersen, E., \& Krashen, S. C., (1990). Developing Communicative Competence in a Second Language [A]. New York: Newbury House, 55-73.

[9] Thompson, B.G. (1975). Sex Differences in Reading Attainment. Educational Researcher, vol.18, pp.16-23. 